\title{
Predictors of blood loss in lung transplant surgery-a single center retrospective cohort analysis
}

\author{
Bastian Grande ${ }^{1,2 \#}$, Pascal Oechslin ${ }^{1 \#}$, Martin Schlaepfer ${ }^{1,3}$, Burkhardt Seifert $^{4}$, Ilhan Inci ${ }^{5}$, Isabelle Opitz ${ }^{5}$, \\ Donat R. Spahn ${ }^{1}$, Walter Weder ${ }^{5}$, Marco Zalunardo ${ }^{1}$
}

${ }^{1}$ Department of Anesthesiology, ${ }^{2}$ Simulation Center, University Hospital Zurich, Ramistrasse 100, 8091 Zurich, Switzerland; ${ }^{3}$ Institute of Physiology, University of Zurich, Winterthurerstrasse 190, 8057 Zurich, Switzerland; ${ }^{4}$ Epidemiology, Biostatistics, and Prevention Institute, University of Zurich, Hirschengraben 84, 8001 Zurich, Switzerland; ${ }^{5}$ Department of Thoracic Surgery, University Hospital Zurich, Ramistrasse 100, 8091 Zurich, Switzerland

Contributions: (I) Conception and design; B Grande, M Zalunardo; (II) Administrative support: B Grande, P Oechslin, M Zalunardo; (III) Provision of study materials or patients: B Grande, P Oechslin, I Inci, I Opitz, M Zalunardo; (IV) Collection and assembly of data: B Grande, P Oechslin, M Schlaepfer; (V) Data analysis and interpretation: M Schlaepfer, B Seifert, M Zalunardo; (VI) Manuscript writing: All authors; (VII) Final approval of manuscript: All authors.

"These authors contributed equally to this work.

Correspondence to: Bastian Grande, MD. Institute of Anesthesiology, University Hospital Zurich, Raemistrasse 100, 8091 Zurich, Switzerland. Email: bastian.grande@usz.ch.

Background: This retrospective study aims to identify clinical predictors of intraoperative blood loss during lung transplantation. While for other surgical specialties predictors of blood loss have been identified such as previous likewise located surgery, poor preoperative health status of patients, blood coagulation status, and use of extra corporeal circulation, predictors of blood loss during lung transplantation are not yet established.

Methods: A total of 326 lung transplants were performed between January 2000 and February 2014 at a tertiary hospital. The primary aim was to associate blood loss with the following potential predictors: pulmonary arterial hypertension, pre- or intraoperative extracorporeal life support (ECLS), previous thoracic surgery, previous lung transplant, and Charlson Comorbidity Index (CCI). Postoperative complications and 30-day mortality were secondary endpoints of the study.

Results: Median estimated blood loss during lung transplant was 1,500 mL (IQR, 1,000-2,875 mL). Pre- and intraoperative ECLS $(\mathrm{P}=0.02, \mathrm{P}<0.001)$ independently increased blood loss by $59 \%$ and $107 \%$, respectively. The higher blood loss during re-transplant marginally missed the significance level $(\mathrm{P}=0.05)$. Pulmonary arterial hypertension, previous thoracic surgery and high CCI were not associated with increased blood loss. As secondary outcomes, postoperative complications were more common in patients with a higher blood loss $(\mathrm{P}=0.04)$ but was not associated with higher 30-day mortality $(\mathrm{P}=0.18)$.

Conclusions: Pre- and intraoperative ECLS were significant risk factors for higher blood loss during lung transplantation. Higher blood loss was associated with higher incidence of postoperative complications but not with a higher 30-day mortality.

Keywords: Blood loss; thoracic surgery; lung transplantation; extracorporeal life support (ECLS)

Submitted Feb 22, 2019. Accepted for publication Sep 27, 2019.

doi: $10.21037 /$ jtd.2019.10.61

View this article at: http://dx.doi.org/10.21037/jtd.2019.10.61 


\section{Introduction}

Recent studies suggest that intraoperative blood lossassociated with the necessity of blood transfusion-has a negative impact on patient outcome after major surgery (1-4). Previous surgery at the same site, poor preoperative health status of the patients, impaired blood coagulation, and the use of extra corporeal circulation play a decisive role in perioperative blood loss. Currently, no specific predictor of blood loss in lung transplantation is known (5). The aim of this retrospective study is to identify factors predictive of increased intraoperative blood loss during lung transplantation.

Considering recent relevant publications in other specialties, previous surgery at the same site was reported to be one of those factors (6-8). We therefore investigated the impact of previous thoracic surgery or previous lung transplantation on blood loss during lung transplantation. If possible, we preferred to examine continuous instead of categorical variables to depict the impact of a factor on blood loss. For example, we avoided setting disease as a variable, but the symptom causing blood loss, thus the impact of pulmonary arterial pressure on blood loss was investigated and not whether or not pulmonary arterial hypertension was present.

Surgery under extracorporeal circulation (ECC) may be accompanied with blood loss due to heparin use, resulting in a prolonged activated clotting time (ACT) and reduced thrombus formation at the surgical site (9-11). While ECC is a requirement for urgent listing of patients, we preferred to highlight the fact whether or not ECC was present or not over the patients listing category.

In multimorbid patients, perioperative complications, including hemorrhage, are common (12). This suggests that multimorbid patients may be susceptible for bleeding, also during lung transplantation. We measured comorbidities with the Charlson Comorbidity Index (CCI) (13).

Mechanistically thinking, an increased pulmonary artery pressure, might increase blood loss during lung transplantation.

The primary aim of this study was to assess predictors of blood loss during lung transplantation. The following factors were investigated: pre- and intraoperative ECC, preexisting pulmonary arterial hypertension, previous thoracic surgery, previous lung transplantation, and CCI.

The secondary aim was the association of increased blood loss with postoperative complications and 30-day mortality.

\section{Methods}

\section{Study design and ethical approval}

This study is a single center retrospective analysis of all patients who underwent lung transplantation between January 2000 and February 2014. The study was approved by the local ethics committee in January 2015 and carries the study number 2014-0579. According to the ethics approval, patient data could be evaluated, in case the patient did not explicitly refuse to have data collected for research purposes.

\section{Data collection}

The data were extracted from the patient's electronical medical records (KISIM, Cistec, Zurich, Switzerland), where the complete patient history can be found. For blood loss estimations, we relied on the anesthesia protocol rather than on the surgical estimation in case the two were incongruent. The data has been analyzed according to the STROBE (STrengthening the Reporting of OBservational studies in Epidemiology) statement.

\section{Statistical analyses}

Continuous variables are presented as median and interquartile range $(\mathrm{IQR})$ or mean \pm standard deviation $(\mathrm{SD})$. Categorical variables are presented as absolute numbers and percentage (\%). Statistical analyses were performed using IBM SPSS Statistics (Version 22.0, IBM Corp, Armonk, NY, USA) and GraphPad Prism 6.0 (GraphPad Inc, La Jolla, CA, USA). In a univariate analysis, potential variables associated with blood loss were explored using the MannWhitney test and Spearman rank correlations. Variables with $\mathrm{P}<0.2$ were included into a stepwise linear regression analysis. For this analysis, blood loss was logarithmically transformed (base 10). Normal distribution of residuals was assessed visually using histograms and p-p plots. In the final model, relative increase of blood loss due to the included factors in percent are reported together with $95 \%$ confidence intervals (CIs). Two-sided $\mathrm{P}$ values $<0.05$ were considered statistically significant.

\section{Surgical methods}

Organ preservation was performed with Perfadex ${ }^{\circledR}$ (Vitrolife, Gothenburg, Sweden). Before ante-grade flush, $500 \mu \mathrm{g}$ prostaglandin $\mathrm{E}_{1}$ (Prostin VR, Upjohn, Puurs, Belgium) 


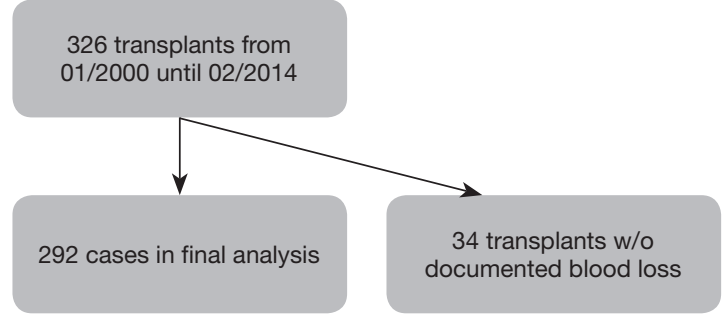

Figure 1 Case analysis.

was injected into the pulmonary artery in all cases. Retrieval of the donor lung was performed en bloc after perfusion. Retrograde flush with Perfadex ${ }^{\circledR}$ was performed during the back-table preparation. The decision to perform size-reduced lung transplantation was made on-site during implantation. For lobar transplants, lobectomy was made on the backtable. The surgical site was reached through bilateral transsternal anterior thoracotomy (clamshell incision) or two separate anterolateral thoracotomies. First, the bronchial anastomosis, followed by venous (atrial cuff), and pulmonary artery anastomosis were sutured. The recipient's main bronchus was cut one ring proximal to the upper lobe bronchus branch. Bronchial arteries were ligated of the peribronchial tissue without electro coagulation. All dissections on the bronchus were performed using "no touch" technique in order to keep the peri-bronchial tissue intact. The donor bronchus was cut back as close as possible to the origin of the upper lobe bronchus with special attention to the peribronchial tissue. Absorbable suture material polydioxanone (PDS, Ethicon Inc., NJ, USA) was used. A continuous suture to the membranous wall (PDS, 4/0) and end-to-end anastomosis with interrupted single stitches (PDS, 4/0) to the cartilaginous part were performed (14).

Bilateral lung transplantation was performed in $96 \%$ of the cases. Due to size-mismatch of the donor and recipient height lobar lung transplantation was performed in 97 cases (33.2\%); bilateral lobar lung transplantation in 37 and unilateral lobar lung transplantation in 60 cases. We used intraoperative extracorporeal life support (ECLS) in $139(47.6 \%)$ transplantations. Twenty recipients were bridged to lung transplantation on extracorporeal membrane oxygenation (ECMO).

\section{Results}

\section{Patient flow}

At the University Hospital Zurich 326 lung transplants
(17 of them were re-transplants) were performed between January 2000 and February 2014. From these, 34 could not be included into the analysis because blood loss was not documented. The final analysis included 292 cases (Figure 1).

\section{Patient and procedure characteristics}

Patients had a mean age of $46 \pm 16$ years, a mean weight of $62 \pm 18 \mathrm{~kg}$, and a mean height of $167 \pm 9 \mathrm{~cm}$. There were 154 $(52.7 \%)$ male and 138 (47.3\%) female patients. Previous thoracic surgery was documented in $105(36.0 \%)$, pulmonary hypertension in $171(58.6 \%)$ cases. Twenty patients $(6.8 \%)$ were on an ECLS prior to transplantation and 139 patients (47.6\%) during transplant surgery. The median blood loss during the procedure was $1,500 \mathrm{~mL}$ (IQR, 1,000-2,875 mL). Details of the patient characteristics can be found in Table 1, and of the procedure characteristics in Table 2.

\section{Risk factors for blood loss during lung transplant}

In a univariate analysis potential associations of factors contributing to hemorrhage have been evaluated: age, weight, height, body mass index (BMI), gender, pulmonary hypertension, preoperative mean pulmonary arterial pressure (mPAP), CCI, previous thoracic surgery, previous lung transplant, pre- and intraoperative ECC, the type of intraoperative ECC [ECMO or cardiopulmonary bypass $(\mathrm{CPB})]$ (Table 3). The potentially associated factors, defined by $\mathrm{P}<0.2$ in the univariate analysis, were preoperative mPAP, CCI, previous thoracic surgery, previous lung transplant, and preoperative and intraoperative ECC. These were included in a stepwise multivariate model (Table 4). We identified pre- and/or intraoperative ECLS $(\mathrm{P}=0.02, \mathrm{P}<0.001$ respectively, Figures 2,3) as risk factors for increased blood loss, retransplantation marginally failed the significance level for increased blood loss $(\mathrm{P}=0.05)$. There was no difference in intraoperative blood loss in patients with an ECMO or a CPB (Figure 3).

Previous intrathoracic surgery, a CCI and pulmonary hypertension were not associated with an increased blood loss.

\section{Secondary outcomes}

Blood loss was associated with a higher number of patients suffering from a postoperative complication, occurring in $181(62.0 \%)$ cases $(\mathrm{P}=0.04)$, but was not associated with a higher 30-day mortality, occurring in 17 (5.8\%) cases $(\mathrm{P}=0.18)$ (Table 5). 
Table 1 Patient characteristics

\begin{tabular}{|c|c|}
\hline Character & Value \\
\hline Age (years) & $46 \pm 16$ \\
\hline Weight (kg) & $62 \pm 18$ \\
\hline \multicolumn{2}{|l|}{ Sex, n (\%) } \\
\hline Male & $154(52.7)$ \\
\hline Female & $138(47.3)$ \\
\hline Preoperative mPAP $(\mathrm{mmHg})$ & $31 \pm 13$ \\
\hline Previous thoracic surgery, $\mathrm{n}(\%)$ & $105(36.0)$ \\
\hline Once & $86(29.5)$ \\
\hline Twice & $12(4.1)$ \\
\hline Three times & $4(1.4)$ \\
\hline Four times & $1(0.3)$ \\
\hline Five times & $2(0.7)$ \\
\hline Previous lung transplant, n (\%) & $16(5.5)$ \\
\hline \multicolumn{2}{|l|}{ Charlson Comorbidity Index, n (\%) } \\
\hline 1 & $177(60.6)$ \\
\hline 2 & 66 (22.6) \\
\hline 3 & $31(10.6)$ \\
\hline 4 & $8(2.7)$ \\
\hline 5 & $2(0.7)$ \\
\hline 6 & $2(0.7)$ \\
\hline 7 & $4(1.4)$ \\
\hline 8 & $1(0.3)$ \\
\hline 9 & $1(0.3)$ \\
\hline
\end{tabular}

mPAP, mean pulmonary artery pressure.

Table 2 Procedure characteristics

\begin{tabular}{lc}
\hline Character & Value \\
\hline Blood loss $(\mathrm{mL})$, median $[\mathrm{IQR}]$ & $1,500[1,000-2,875]$ \\
Necessity of ECLS preoperatively, $\mathrm{n}(\%)$ & $20(6.8)$ \\
Necessity of ECLS intraoperatively, $\mathrm{n}(\%)$ & $139(47.6)$ \\
ECMO & $129(44.2)$ \\
Classic cardiopulmonary bypass & $10(3.4)$ \\
\hline
\end{tabular}

IQR, interquartile range; ECLS, extracorporeal life support device; ECMO, extracorporeal membrane oxygenation.
Table 3 Univariate analysis of associations with blood loss during lung transplant surgery

\begin{tabular}{lc}
\hline Factor & P value \\
\hline Age & 0.79 \\
Weight & 0.54 \\
Height & 0.51 \\
BMl & 0.71 \\
Gender & 0.93 \\
Pulmonary hypertension (mPAP $>25 \mathrm{mmHg})$ & 0.24 \\
Preoperative mPAP & 0.04 \\
CCl & 0.06 \\
Previous thoracic surgery & 0.18 \\
Previous lung transplant & 0.02 \\
ECC preoperative & $<0.001$ \\
ECC intraoperative & $<0.001$ \\
Type of intraoperative ECC (CPB or ECMO) & 0.22 \\
\hline
\end{tabular}

$\mathrm{BMI}$, body mass index; mPAP, mean pulmonary artery pressure; $\mathrm{CCl}$, Charlson Comorbidity Index; ECC, extracorporeal circulation; $\mathrm{CPB}$, cardiopulmonary bypass; ECMO, extracorporeal membrane oxygenation.

Table 4 Multivariate analysis of factors associated with blood loss during lung transplant surgery

\begin{tabular}{lcc}
\hline Factor & Relative increase $(95 \% \mathrm{Cl})$ & $\mathrm{P}$ value \\
\hline ECC intraoperative & $107 \%(72 \%$ to $150 \%)$ & $<0.001$ \\
ECC preoperative & $59 \%(7 \%$ to $136 \%)$ & 0.02 \\
Previous lung transplant & $50 \%(1 \%$ to $124 \%)$ & 0.05 \\
\hline ECC, extracorporeal circulation.
\end{tabular}

\section{Discussion}

This retrospective study reveals that both previous lung transplantation and pre- or an intraoperative ECLS are independent risk factors for increased blood loss in lung transplant surgery. In addition, we were able to demonstrate that a high blood loss is associated with a higher rate of postoperative complications.

Surprisingly, neither comorbidities nor an elevated mPAP at the beginning of the transplantation were associated with 


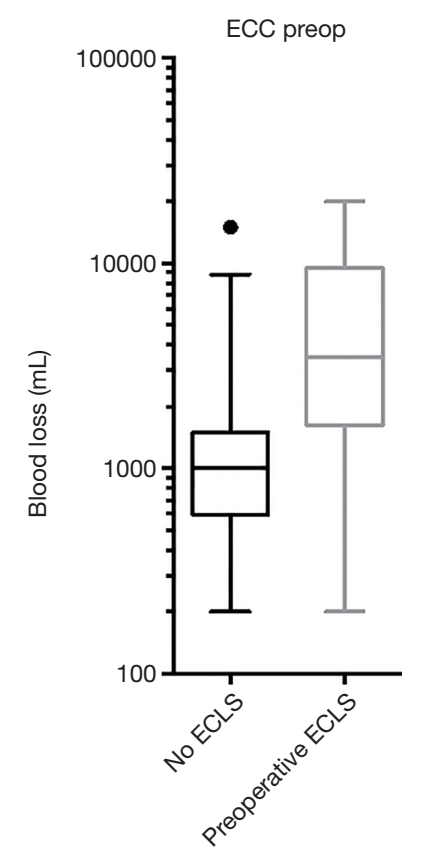

Figure 2 Blood loss with and without preoperative ECLS. ECLS, extracorporeal life support; ECC, extracorporeal circulation.

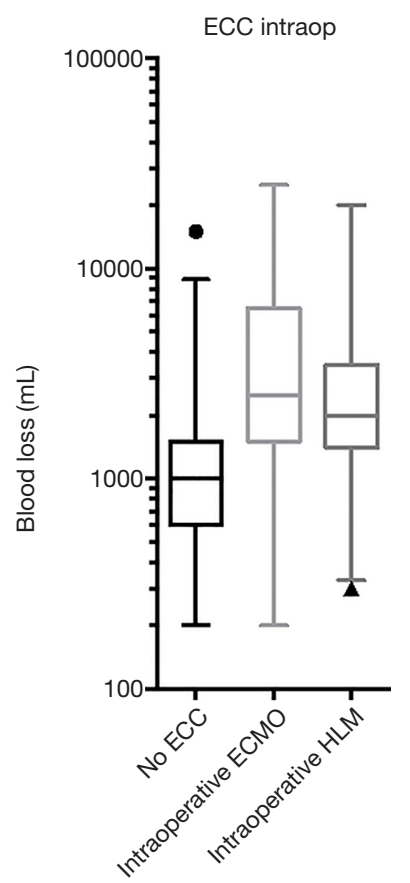

Figure 3 Blood loss with intraoperative HLM and ECMO and without ECC. ECC, extracorporeal circulation; ECMO, extracorporeal membrane oxygenation; HLM, heart-lung machine.
Table 5 Secondary outcomes associated with blood loss during lung transplant surgery (univariate analysis)

\begin{tabular}{lc}
\hline Secondary outcome & P value \\
\hline Death within 30 days & 0.18 \\
Postoperative complications & 0.04 \\
\hline
\end{tabular}

increased hemorrhage. The 30-day mortality seems to be unaffected by the amount of blood loss, but the number of cases was low and therefore the study may lack the power for this outcome.

It is interesting to note that the use of intraoperative ECC was associated with increased blood loss, but there was no difference between the use of an ECMO (using only a low dose heparinization with a target ACT of 150 to $180 \mathrm{~s}$ ) and the use of a heart-lung machine (HLM) (using full heparinization with a higher target ACT of 250 to $300 \mathrm{~s}$ ). We cannot exclude, that besides heparinization other factors might have impact on blood loss, such as surgical techniques or a different patient population in the two groups. Comparing ECMO and HLM, recent studies focused only on transfusion requirements but not on blood loss. Concerning transfusion requirements ECMO seems to be the better option (15-17) but two studies report otherwise $(18,19)$. However, Burdett et al. investigated blood loss in single lung transplants with and without the use of CPB and found significantly greater blood loss in the CPB group (20).

The identification of factors for increased intraoperative blood loss is interesting from various points of view: on one hand, this knowledge might serve as a criterion for or against listing patients who otherwise appear marginal and might therefore be at risk for not surviving the transplantation. On the other hand, known risk factors could help to be alert for blood loss and for early and even more stringent coagulation management and cell salvage.

Finally, to minimize blood loss in patients at high risk for elevated intraoperative blood loss, the most experienced surgeon should be in charge for the critical surgical steps.

\section{Limitations}

In addition to the usual problems of being a retrospective analysis, the investigation has been limited to a single center. The selection of patients has been different over time. At 
first, patients with a simple anatomy and selective organs (to avoid a size mismatch) were chosen, which might have facilitated the procedure and minimized blood loss, whereas towards the end of the observation period more complex patients have been on the transplant list. Furthermore, the practice, indication and use of ECLS have become more liberal and frequent throughout the study period.

\section{Conclusions}

Previous lung transplant as well as pre- and intraoperative treatment with ECLS are independent factors for increased blood loss in lung transplantation, which is associated with increased complication rate, but not with increased 30-day mortality.

\section{Acknowledgments}

None.

\section{Footnote}

Conflicts of Interest: The authors have no conflicts of interest to declare.

Ethical Statement: The authors are accountable for all aspects of the work in ensuring that questions related to the accuracy or integrity of any part of the work are appropriately investigated and resolved. The study was approved by the local ethics committee in January 2015 and carries the study number 2014-0579. According to the ethics approval, patient data could be evaluated, in case the patient did not explicitly refuse to have data collected for research purposes.

\section{References}

1. Carson JL, Poses RM, Spence RK, et al. Severity of anaemia and operative mortality and morbidity. Lancet 1988;1:727-9.

2. Spence RK, Carson JA, Poses R, et al. Elective surgery without transfusion: influence of preoperative hemoglobin level and blood loss on mortality. Am J Surg 1990;159:320-4.

3. Weber D, Cottini SR, Locher P, et al. Association of intraoperative transfusion of blood products with mortality in lung transplant recipients. Perioper Med (Lond) 2013;2:20.
4. Zalunardo MP, Thalmann C, Seifert B, et al. Impact of preoperative right-ventricular function and platelet transfusion on outcome after lung transplantation. Eur J Cardiothorac Surg 2011;39:538-42.

5. Wang Y, Kurichi JE, Blumenthal NP, et al. Multiple variables affecting blood usage in lung transplantation. $\mathrm{J}$ Heart Lung Transplant 2006;25:533-8.

6. Steib A, Freys G, Lehmann C, et al. Intraoperative blood losses and transfusion requirements during adult liver transplantation remain difficult to predict. Can J Anaesth 2001;48:1075-9.

7. Bang SR, Ahn HJ, Kim GS, et al. Predictors of high intraoperative blood loss derived by simple and objective method in adult living donor liver transplantation. Transplant Proc 2010;42:4148-50.

8. Hatzidakis AM, Mendlick RM, McKillip T, et al. Preoperative autologous donation for total joint arthroplasty. An analysis of risk factors for allogenic transfusion. J Bone Joint Surg Am 2000;82:89-100.

9. Bachmann F, McKenna R, Cole ER, et al. The hemostatic mechanism after open-heart surgery. I. Studies on plasma coagulation factors and fibrinolysis in 512 patients after extracorporeal circulation. J Thorac Cardiovasc Surg 1975;70:76-85.

10. Murphy DA, Hockings LE, Andrews RK et al. Extracorporeal membrane oxygenation-hemostatic complications. Transfus Med Rev 2015;29:90-101.

11. Bhaskar B, Zeigenfuss M, Choudhary J, et al. Use of recombinant activated Factor VII for refractory after lung transplant bleeding as an effective strategy to restrict blood transfusion and associated complications. Transfusion 2013;53:798-804.

12. Longo WE, Virgo KS, Johnson FE, et al. Risk factors for morbidity and mortality after colectomy for colon cancer. Dis Colon Rectum 2000;43:83-91.

13. Charlson ME, Pompei P, Ales KL, et al. A new method of classifying prognostic comorbidity in longitudinal studies: development and validation. J Chronic Dis 1987;40:373-83.

14. Inci I, Schuurmans MM, Boehler A, et al. Zurich University Hospital lung transplantation programme: update 2012. Swiss Med Wkly 2013;143:w13836.

15. Ius F, Kuehn C, Tudorache I, et al. Lung transplantation on cardiopulmonary support: venoarterial extracorporeal membrane oxygenation outperformed cardiopulmonary bypass. J Thorac Cardiovasc Surg 2012;144:1510-6.

16. Machuca TN, Collaud S, Mercier O, et al. Outcomes of intraoperative extracorporeal membrane oxygenation 
versus cardiopulmonary bypass for lung transplantation. J Thorac Cardiovasc Surg 2015;149:1152-7.

17. Biscotti M, Yang J, Sonett J, et al. Comparison of extracorporeal membrane oxygenation versus cardiopulmonary bypass for lung transplantation. J Thorac Cardiovasc Surg 2014;148:2410-5.

18. Bermudez CA, Shiose A, Esper SA, et al. Outcomes of intraoperative venoarterial extracorporeal membrane oxygenation versus cardiopulmonary bypass during lung transplantation. Ann Thorac Surg 2014;98:1936-42;

Cite this article as: Grande B, Oechslin P, Schlaepfer M, Seifert B, Inci I, Opitz I, Spahn DR, Weder W, Zalunardo M. Predictors of blood loss in lung transplant surgerya single center retrospective cohort analysis. J Thorac Dis 2019;11(11):4755-4761. doi: 10.21037/jtd.2019.10.61 discussion 1942-3.

19. Bittner HB, Binner C, Lehmann S, et. al. Replacing cardiopulmonary bypass with extracorporeal membrane oxygenation in lung transplantation operations. Eur J Cardiothorac Surg 2007;31:462-7; discussion 467.

20. Burdett C, Butt T, Lordan J, et al. Comparison of single lung transplant with and without the use of cardiopulmonary bypass. Interact Cardiovasc Thorac Surg 2012;15:432-6; discussion 436. 